\title{
VIBRA trial - Effect of village-based refill of ART following home-based same-day ART initiation vs clinic-based ART refill on viral suppression among individuals living with HIV: protocol of a cluster-randomized clinical trial in rural Lesotho
}

\author{
Alain Amstutz 1,2,3, Thabo Ishmael Lejone ${ }^{4}$, Lefu Khesa ${ }^{4}$, Josephine Muhairwe ${ }^{4}$, Bienvenu Lengo Nsakala ${ }^{4}$, \\ Katleho Tlali ${ }^{4,5}$, Moniek Bresser ${ }^{1,2}$, Fabrizio Tediosi ${ }^{1,2}$, Mathebe Kopo ${ }^{4}$, Mpho Kao ${ }^{4}$, Thomas Klimkait ${ }^{2,6}$, \\ Manuel Battegay ${ }^{2,3}$, Tracy Renée Glass ${ }^{1,2}$ and Niklaus Daniel Labhardt ${ }^{1,2,3^{*}}$ (D)
}

\begin{abstract}
Background: There is a need for evaluating community-based antiretroviral therapy (ART) delivery models to improve overall performance of HIV programs, specifically in populations that may have difficulties to access continuous care. This cluster-randomized clinical trial aims to evaluate the effectiveness of a multicomponent differentiated ART delivery model (VIBRA model) after home-based same-day ART initiation in remote villages in Lesotho, southern Africa.
\end{abstract}

Methods/design: The VIBRA trial (VIllage-Based Refill of ART) is a cluster-randomized parallel-group superiority clinical trial conducted in two districts in Lesotho, southern Africa. Clusters (i.e., villages) are randomly assigned to either the VIBRA model or standard care. The clusters are stratified by district, village size, and village access to the nearest health facility. Eligible individuals (HIV-positive, aged 10 years or older, and not taking ART) identified during community-based HIV testing campaigns are offered same-day home-based ART initiation. The intervention clusters offer a differentiated ART delivery package with two features: (1) drug refills and follow-ups by trained and supervised village health workers (VHWs) and (2) the option of receiving individually tailored adherence reminders and notifications of viral load results via SMS. The control clusters will continue to receive standard care, i.e., collecting ART refills from a clinic and no SMS notifications. The primary endpoint is viral suppression 12 months after enrolment. Secondary endpoints include linkage to and engagement in care. Furthermore, safety and cost-effectiveness analyses plus qualitative research are planned. The minimum target sample size is 262 participants. The statistical analyses will follow the CONSORT guidelines. The VIBRA trial is linked to another trial, the HOSENG (HOme-based SElf-testiNG) trial, both of which are within the GET ON (GETing tOwards Ninety) research project.

(Continued on next page)

\footnotetext{
* Correspondence: n.labhardt@swisstph.ch

${ }^{1}$ Clinical Research Unit, Department of Medicine, Swiss Tropical and Public

Health Institute, Socinstrasse 57, 4051 Basel, Switzerland

2University of Basel, 4051 Basel, Switzerland

Full list of author information is available at the end of the article
}

(c) The Author(s). 2019 Open Access This article is distributed under the terms of the Creative Commons Attribution 4.0 International License (http://creativecommons.org/licenses/by/4.0/), which permits unrestricted use, distribution, and reproduction in any medium, provided you give appropriate credit to the original author(s) and the source, provide a link to the Creative Commons license, and indicate if changes were made. The Creative Commons Public Domain Dedication waiver (http://creativecommons.org/publicdomain/zero/1.0/) applies to the data made available in this article, unless otherwise stated. 
(Continued from previous page)

Discussion: The VIBRA trial is among the first to evaluate the delivery of ART by VHWs immediately after ART initiation. It assesses the entire HIV care cascade from testing to viral suppression. As most countries in sub-Saharan Africa have cadres like the VHW program in Lesotho, this model — if shown to be effective- has the potential to be scaled up. The system impact evaluation will provide valuable cost estimations, and the qualitative research will suggest how the model could be further modified to optimize its impact.

Trial registration: Clinicaltrials.gov, NCT03630549. Registered on 15 August 2018.

Keywords: HIV, cluster randomized controlled trial, village health worker, community health worker, home-based, differentiated care and delivery, antiretroviral therapy, Lesotho, Southern Africa, multi component intervention

\section{Introduction}

Multiple studies conducted in sub-Saharan Africa (SSA) report high attrition from HIV testing to linkage to care and suboptimal engagement in care [1-7]. There are many reasons for this, but structural barriers such as the time-consuming and expensive (pre-)antiretroviral therapy (ART) visits and subsequent regular drug refill visits represent major impediments, especially in rural settings [8-16]. Therefore, the World Health Organization (WHO), international funders, national policies in subSaharan Africa, and the research community are calling for differentiated ART delivery models that are adapted to the local context. These include further shifting of tasks and the decentralization of care [17-23].

The CASCADE trial was a randomized clinical trial on the effect of offering same-day ART vs the usual referral to a health facility during home-based HIV testing on linkage to care and viral suppression among adults with HIV in Lesotho. This trial evaluated same-day ART initiation in the community and found significantly improved outcomes along the entire HIV care cascade [24]. However, the CASCADE trial did not quite reach the targeted 90\% linkage to and engagement in care rates after participants had tested positive for HIV and were offered same-day ART initiation at home. The VIBRA (Village-Based Refill of ART) trial builds on these findings, specifically addressing the challenges after same-day home-based ART initiation.

For patients who are stable on ART, decentralization of care to the community level and the shifting of care tasks to lay health workers has been shown to be feasible, cost-effective, and acceptable [25-40]. The WHO, thus, endorses the recruitment of community health workers as a strategy to mitigate the impact of the severe shortage of nurses and doctors in rural Africa on healthcare coverage [41]. Moreover, the United Nations Program on HIV/AIDS (UNAIDS) launched a plan to recruit 2 million community health workers in Africa to support its strategy [42]. Lesotho, a small landlocked country surrounded by South Africa, has the secondhighest adult HIV prevalence globally (25.6\%). More than $70 \%$ of its population live in rural areas where there is a shortage of doctors and nurses [43, 44]. A longstanding public sector cadre of lay personnel, called village health workers (VHWs), was introduced in 1978 and more than $4000 \mathrm{VHWs}$ are currently successfully operating in all districts of Lesotho [45].

We designed the VIBRA model in close collaboration with local stakeholders. It is a multicomponent differentiated ART delivery package that builds on the VHW program and SMS technology. In this manuscript, we describe the protocol for a cluster-randomized clinical trial that aims to evaluate the effectiveness of the VIBRA model following same-day home-based ART initiation in rural communities in Lesotho.

\section{Methods/design \\ Setting}

The VIBRA trial will be conducted in the districts of Butha-Buthe and Mokhotlong in northern Lesotho, in the catchment areas of 22 health facilities. Both districts are mostly rural with an estimated population of 220,000, mainly living in villages scattered over a mountainous area of $5842 \mathrm{~km}^{2}$. The trial utilizes the long-standing VHW country program. VHWs are members of and appointed by the community to provide a package of basic services at the household level, although they have no formal professional health education. They are elected by the village members, complete 2 weeks of training followed by periodic refresher courses, and are supported and supervised by the health center staff for the corresponding catchment area. Most are supported by the Ministry of Health and receive a monthly stipend of USD 20.

\section{Design}

The VIBRA trial is a cluster-randomized superiority trial. The trial is linked to another trial, the HOSENG (HOme-based SElf-testiNG) trial [76]. Together, HOSENG and VIBRA constitute the GET ON (GETing tOwards Ninety) research project. Reasons for this interlinked design are that both trials rely on interventions involving VHWs, who need to be randomized and specifically trained, and that the HOSENG trial provides 
one of the recruitment platforms for VIBRA. Thus, the two trials are based on the same cluster randomization and will run in parallel. This design allows us to assess the entire HIV care cascade in one larger project. A cluster-randomized design was chosen because of the reliance on VHWs and the high risk of cross-contamination between study arms if randomization were done at the individual level.

\section{Cluster randomization, screening of study participants, eligibility and interventions}

Cluster eligibility, cluster sampling, cluster randomization, and the HIV testing campaign are described in detail in the interlinked HOSENG study protocol, which has been published separately [76]. In short, before the trial started, the eligible clusters (i.e., villages) were randomized into four groups: (1) VIBRA control and HOSENG control, (2) VIBRA control and HOSENG intervention, (3) VIBRA intervention and HOSENG control, and (4) VIBRA intervention and HOSENG intervention. The randomization is stratified by district, village size ( $\geq 30 \mathrm{vs}<30$ households) and access to the nearest health facility (easy vs hard to reach, defined by needing to cross a mountain or river, or > $10 \mathrm{~km}$ away from the health facility), in a 1:1:1:1 allocation ratio with block sizes of 4 . In total, 159 clusters were identified and randomized into one of the four groups. When enrolment started, 25 clusters per group, i.e., 50 clusters per arm (VIBRA intervention vs control) were available to the local study team with the option to add more clusters as needed to reach the recruitment goals.

Campaign teams consisting of counsellors and one study nurse visit the rural villages (clusters) in the two study districts. The teams offer HIV testing and counselling and multi-disease screening and prevention. Household members who are eligible for and consent, undergo HIV testing by the counselors according to national HIV testing guidelines [46]. All household members with a confirmed HIV-positive result and not taking ART are screened by the study nurse for VIBRA eligibility according to the criteria in Table 1.
If a patient is eligible for VIBRA and consents, the study nurse offers same-day home-based ART initiation and proposes follow-up care according to the cluster assignment. As successfully implemented through our previous trial and recommended by the national guidelines, same-day home-based ART initiation, using the national standard first-line ART regimen, will be provided in both arms $[19,24]$. If individuals are not eligible for the VIBRA trial and thus, not eligible for same-day standard first-line ART initiation, they are referred to the health facility. Features of same-day ART initiation are outlined in Table 2.

\section{Intervention clusters}

The participants in the intervention clusters are offered the two features of the VIBRA model. The first feature is the possibility of village-based ART visits and refills through the VHWs, with routine clinic visits required only at 6 and 12 months after ART initiation. The second is the offer of receiving a tailored SMS intervention. Figure 1 summarizes the VIBRA model.

If participants in the intervention clusters choose the village-based ART visits and refills, they are given an appointment for a first clinical visit to the VHW 12 to 16 days after the home-based ART initiation. At each visit, the VHW follows the same paper-based checklist (provided as Additional file 1: eForm title "Follow-up") written in the local language (Sesotho). By following the checklist, the VHW documents: (a) the patient's symptoms to alert them to potential drug toxicity, opportunistic infections, or immune reconstitution inflammatory syndrome, (b) adherence to ART, and (c) any visits to other health facilities. To ensure safe and high-quality clinical management, participants in intervention clusters will not only be linked to their VHW, but will also be under the care of the community ART nurse (CAN) for the relevant district. If any question on the checklist triggers an alert, the VHW will inform their CAN. CANs are nurses who are experienced in HIV care. One CAN per district has been hired. The VHWs and CANs will have a list of the participants for whom they are

Table 1 Eligibility criteria for VIBRA trial

\begin{tabular}{|c|c|}
\hline Inclusion criteria & Exclusion criteria \\
\hline $\begin{array}{l}\text { Individual is a member of a visited household, i.e. the individual } \\
\text { is (a) acknowledged by the household head or their representative } \\
\text { as part of the household and (b) sleeps in the household regularly } \\
\text { (at least once a month) }\end{array}$ & HIV-positive individual is on ART or stopped less than 30 days ago \\
\hline $\begin{array}{l}\text { Individual is confirmed HIV-positive, as determined by two reactive } \\
\text { blood-based HIV antibody tests according to national guidelines }\end{array}$ & $\begin{array}{l}\text { HIV-positive individual is physically, mentally, or emotionally not able to } \\
\text { participate in the study, in the opinion of the study nurse }\end{array}$ \\
\hline $\begin{array}{l}\text { Individual has never taken ART (ART naïve) or has stopped ART more } \\
\text { than } 30 \text { days prior (ART defaulter according to national guidelines) }\end{array}$ & $\begin{array}{l}\text { HIV-positive individual is in care for hypertension or diabetes; documentation } \\
\text { or proof of medication is needed }\end{array}$ \\
\hline Individual is $\geq 10$ years old and body weight $\geq 35 \mathrm{~kg}$ & HIV-positive individual wishes to get care outside the two study districts \\
\hline
\end{tabular}




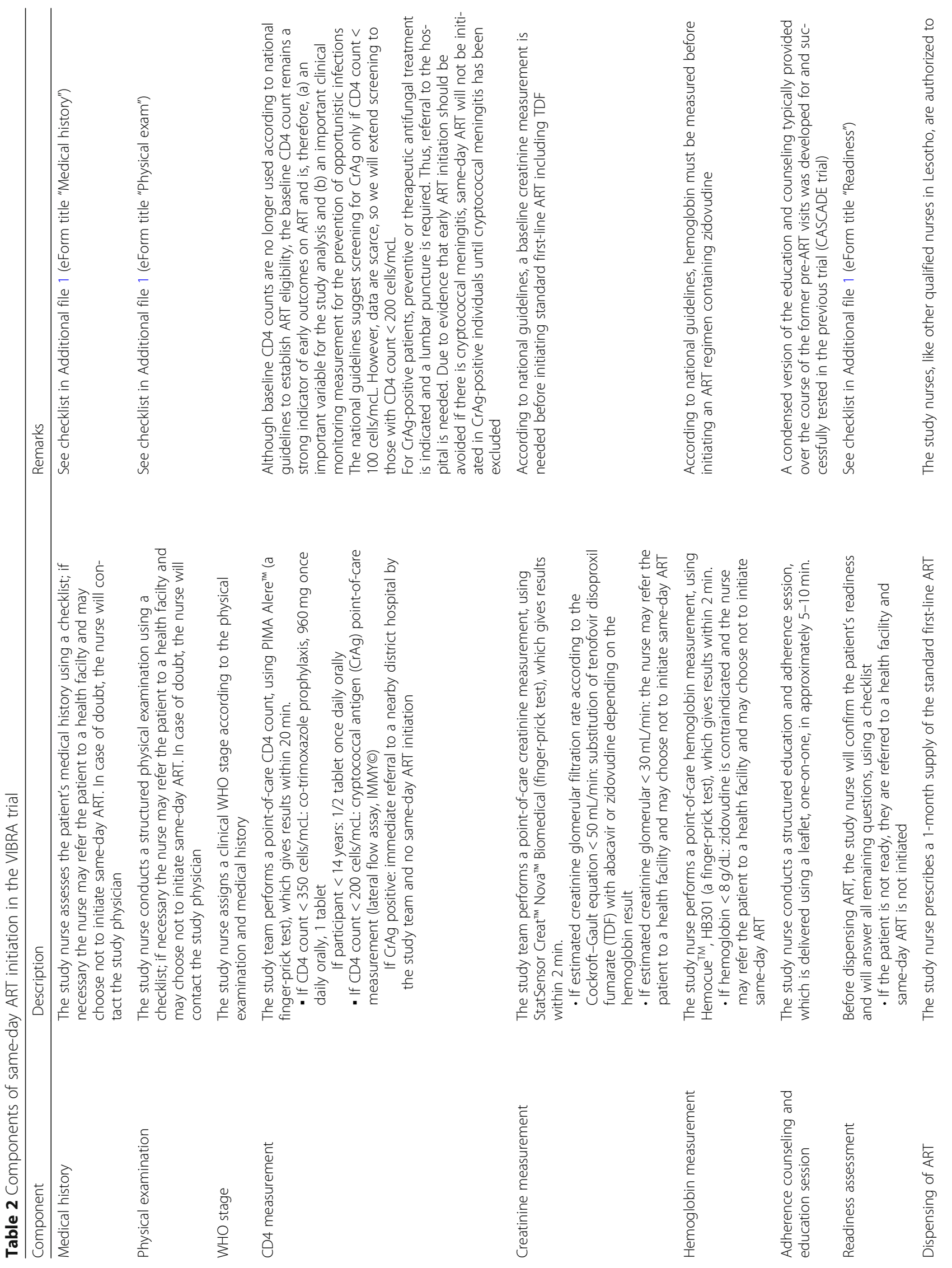




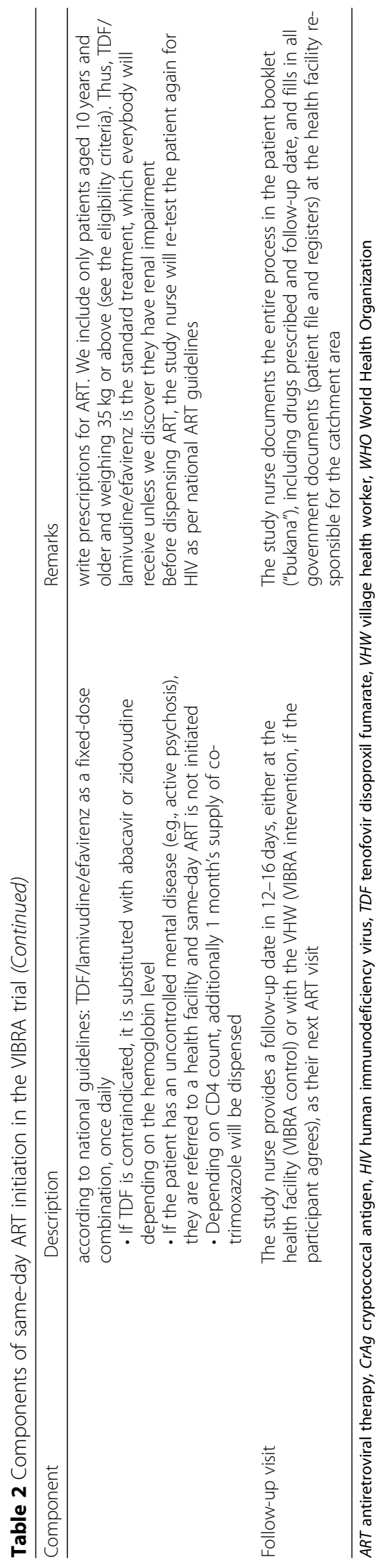




\begin{tabular}{|c|c|c|c|c|}
\hline & & $\begin{array}{l}\text { VIBRA Control } \\
\text { (Standard of care) }\end{array}$ & & $\begin{array}{l}\text { VIBRA Intervention } \\
\text { (Offer of VIBRA model) }\end{array}$ \\
\hline 1 & Offer 0 & home-based same-day ART initiation & Offer of & home-based same-day ART initiation \\
\hline \multirow{5}{*}{2} & \multicolumn{2}{|c|}{ Clinic-based ART visit/refill } & \multicolumn{2}{|c|}{ Offer of village-based ART visit/refill } \\
\hline & 曹 WHEN & Follow-up interval of max. 3 months & 曹 WHEN & Follow-up interval of max. 3 months \\
\hline & 18 WHERE & Nurse-led health facility & \& WHERE & $\begin{array}{l}\text { At the VHW } \\
\text { Except at } 6 \text { and } 12 \text { months follow-up: visit at health } \\
\text { facility for laboratory assessment (esp. VL=viral load) }\end{array}$ \\
\hline & : พно & Nurse & : พно & VHW \\
\hline & E WHAT & $\begin{array}{l}\text { Screening for opportunistic infections (esp. TB) and } \\
\text { ART-related toxicities, adherence assessment, ART } \\
\text { (+CTX/IPT) dispensing }\end{array}$ & E WHAT & $\begin{array}{l}\text { Screening for opportunistic infections (esp. TB) and } \\
\text { ART-related toxicities, adherence assessment, ART } \\
\text { (+CTX/IPT) dispensing }\end{array}$ \\
\hline \multirow{4}{*}{3} & \multirow{4}{*}{\multicolumn{2}{|c|}{$\begin{array}{l}\text { No SMS intervention } \\
\text { However, SMS might be used to follow-up patients in order to ensure } \\
\text { laboratory assessments at } 6 \text { and } 12 \text { months. }\end{array}$}} & \multicolumn{2}{|c|}{ Offer of Individually customized SMS } \\
\hline & & & 肇WHEN & Monthly and after VL measurement \\
\hline & & & : WHo & Automatically sent out from VL database \\
\hline & & & E WHAT & $\begin{array}{l}\text { a) Monthly reminder to adhere to ART } \\
\text { b) Individually tailored SMS according to VL result }\end{array}$ \\
\hline
\end{tabular}

Fig. 1 Procedures for the VIBRA intervention and control clusters

responsible. A VHW will be allowed to dispense ART only to participants on their list. Like the health facilites, the VHW will provide a supply of drugs for 1-3 months at each visit. Participants are, however, encouraged to visit the VHW or the clinic at any time when problems or questions arise. Six months after ART initiation, the participant must attend the clinic for the first time for a laboratory assessment.

VHWs have monthly meetings at the health facility with a designated facility staff member. The VIBRA model will utilize these existing meetings and the CAN (or a representative) will join and provide support. These meetings are a platform for reviewing patient files. Patients can be up-referred (to the health facility) or down-referred (to the VHW). If a patient misses an ART visit, they will be traced by the VHW using a standardized tracking tool (provided as Additional file 1: eForm title "Tracing form").

All VHWs in the intervention clusters will be trained to deliver the VIBRA model: (a) to dispense ART (and other co-medications such as cotrimoxazole), (b) to screen for ART-related adverse events and drug toxicities, (c) to screen for co-infection (especially tuberculosis), (d) to assess adherence, (e) to understand the referral algorithm in case there is clinical deterioration, (f) to address disclosure and keep confidentiality, and ( $\mathrm{g}$ ) to perform basic data entry for the checklists. This training will last for 2-3 days.

If participants in the intervention clusters choose the SMS intervention, they will receive monthly reminder
SMS in Sesotho to adhere to ART ("Take your medication regularly as prescribed and don't run out of medication") and a viral load (VL) result-triggered SMS after the 6- and 12-month follow-up visits:

- If undetectable VL (<20 copies/mL): "Congratulations, your lab test was good. Keep it up!"

- If detectable VL ( $\geq 20$ copies/mL): "Your lab test results are back. Make sure to come to the health facility as soon as possible and remind the nurse about your lab test."

- If technical failure of VL measurement: "The lab test was unsuccessful. Make sure to come to the health facility as soon as possible and remind the nurse about your lab test."

To maintain participant confidentiality, messages will not explicitly mention HIV or HIV care. Participants are not asked to confirm receipt of messages or to reply and can choose at any time to opt out from receiving messages.

\section{Control clusters}

Participants in the control clusters are offered standard care, i.e., ART visits and refills at the health facility and no SMS intervention. They receive an appointment for a first clinic visit within 12 to 16 days of the home-based ART initiation. For each visit, a staff member at the 
health facility will fill in the same checklist as the VHWs. Study participants will not be offered any other differentiated delivery models.

\section{Endpoints}

The primary endpoint is viral suppression $(<20$ copies $/ \mathrm{mL})$ at 12 months, defined as the proportion of all participants with a suppressed VL 12 months (range: 10-15 months) after enrollment. Although this is a cluster-randomized trial, the analysis will be at individual level with viral suppression as a binary outcome. VL will be measured in plasma using the COBAS TaqMan ${ }^{\circ}$ HIV-1 Test, v2.0 (Roche Diagnostics). Secondary and exploratory endpoints as well as the long-term follow-up are outlined in Table 3.

\section{Additional research within the project}

We will conduct biomolecular research within this project. We will assess the prevalence of major drug resistance mutations in baseline samples and on all samples with unsuppressed VL at 12 months. Participants who start ART at home during the testing campaign but subsequently never link to care will be specifically traced to assess the development of drug resistance mutations.

Qualitative research is planned alongside the project to provide important contextual data and an in-depth exploration of the community response to the intervention. For a qualitative case-control study, a random sample from the VIBRA intervention clusters will be chosen. Cases will be participants who refuse village-based ART refills through the VHW, while controls will be participants who accept village-based ART refills through the VHW. Moreover, we will conduct standardized interviews with a random sample of all stakeholders involved in delivering this new ART care and delivery model.

We will perform a system impact evaluation and costeffectiveness analysis to estimate the impact of the VIBRA intervention on health benefits and costs. First, we will assess the direct costs of the interventions. Secondly, we will assess the cost-effectiveness of the VIBRA model. Thirdly, we will assess the economic burden of the interventions to the participants, i.e., including both direct costs and the opportunity costs of their time. The assessment of direct costs will include staff costs (campaign staff, clinical staff, laboratory staff, VHWs, and CANs), personnel training costs, the cost of equipment (costs of HIV tests, costs of ART and other drugs, and laboratory costs including the point-of-care tests at enrolment), and non-medical costs for the participant. The VIBRA model is expected to reduce the number of clinic visits because of the VHWbased ART refill. There are expected to be fewer unscheduled visits because the intervention may lead to a better and more sustained clinical outcome. This would decrease costs for the health system and the participants (i.e., time required to access care, lost working time while accessing care, and additional expenses while accessing care).

\section{Data collection and management, biologic material, and follow-ups}

The VHWs and the healthcare staff at the health facilities will collect data from scheduled and unscheduled ART visits on standardized paper study forms (case report forms), which are the source documents. Case report forms will be collected regularly by the study team and entered into a password-protected database (MACRO, Elsevier). Similarly, data relevant for the SMS intervention will be entered and stored in a separate encrypted and password-protected online database. This offers the possibility of sending out SMS messages automatically and is connected to the district laboratory database containing the VL results. The platform and data are housed on a dedicated server in a data center in Switzerland (Interxion, managed by Hostpoint AG), which meets FINMA-RS 08/07 requirements, is ISO27001-certified, and encrypts data in-transit with SSL and all patient names at-rest using OpenSSL with the AES-256-CTR cipher method. Access to both platforms is strictly limited and regulated through personal user profiles. SMS messages are dispatched using the trusted third-party provider Twilio, headquartered in the United States and certified with the EU-U.S. and Swiss-U.S. Privacy Shield Framework. Consent forms will be stored securely in the headquarters of the study center (the SolidarMed office in Butha-Buthe, Lesotho). Participant files will be maintained in storage for at least 10 years after completion of the study.

Participants in all clusters undergo HIV testing and phlebotomy at enrolment, and phlebotomy at 6 and 12 months. For each participant, blood samples coded with the participant's study ID will be stored at $-80{ }^{\circ} \mathrm{C}$ at the laboratory in Butha-Buthe Hospital. All samples collected fall under the biobank and material transfer agreement, which has been approved by the ethics committees in Switzerland and Lesotho. Figure 2 is the SPIRIT flow diagram and has an overview of data collection, laboratory assessments, and follow-up visits (Additional file 2).

\section{Sample size}

Based on data from the CASCADE trial [24], we expect the proportion of patients engaged in care with documented viral suppression 12 months after same-day ART initiation in the control arm to be approximately 50\% and we expect to recruit on average 4 individuals per cluster. Assuming a $20 \%$ refusal and ineligibility rate, about 400 individuals need to be screened to identify 320 eligible individuals and $90 \%$ power to detect a $20 \%$ increase in the intervention group. We plan to enroll a minimum of 262 patients to ensure a minimum power 
Table 3 Secondary and exploratory endpoints of the VIBRA trial

\begin{tabular}{|c|c|c|c|}
\hline & Definition & $\begin{array}{l}\text { Time point following } \\
\text { enrolment }\end{array}$ & Remarks \\
\hline \multicolumn{4}{|l|}{ Secondary endpoints } \\
\hline $\begin{array}{l}\text { Viral suppression }<20 \text { copies/ } \\
\mathrm{mL}\end{array}$ & $\begin{array}{l}\text { Proportion of all participants with viral } \\
\text { suppression }(<20 \text { copies } / \mathrm{mL})\end{array}$ & 6 (range: $5-8$ ) months & \\
\hline $\begin{array}{l}\text { Viral suppression }<1000 \text { copies/ } \\
\text { mL }\end{array}$ & $\begin{array}{l}\text { Proportion of all participants with viral } \\
\text { suppression }(<1000 \text { copies } / \mathrm{mL})\end{array}$ & $\begin{array}{l}6 \text { (range: } 5-8 \text { ) and } 12 \text { (range: } \\
10-15) \text { months }\end{array}$ & $\begin{array}{l}\text { Some of the remote health facilities in } \\
\text { our study districts face regular } \\
\text { challenges in sending blood samples to } \\
\text { a government hospital. To ensure there } \\
\text { are sufficient VL measurements among } \\
\text { our study participants, these health } \\
\text { facilities will be equipped with dried- } \\
\text { blood-spot kits as a backup for VL mea- } \\
\text { surements. According to WHO, the rec- } \\
\text { ommended threshold for treatment } \\
\text { failure using a dried blood spot is } 1000\end{array}$ \\
\hline
\end{tabular}

Linkage to care

Engagement in and retention in care

All-cause mortality

Lost to follow-up

Transfer out

Serious adverse event

Compliance with the protocol procedure

Overall effect of HOSENG + VIBRA
Proportion of all participants attending their first clinic- or VHW-based ART visit at least once within the given period

Proportion of all participants active in care at a health facility or with a VHW a) Within 1 month

b) Within 3 months

6 (range: 5-8) and 12 (range: 10-15) months
Proportion of participants dead for any reason

Proportion of all participants lost to follow-up

Proportion of all participants who transferred to another health facility (other than the one they were initially attached to) with a known outcome

Proportion of patients with a serious adverse event
12 (range: 10-15) months

12 (range: 10-15) months

12 (range: 10-15) months

Within 12 months

Proportion of ART refills and ART visits per participant according to the protocol schedule, at the VHW and the health facility

Overall effect of the combined interventions HOSENG and VIBRA (arm 4
12 (range: 10-15) months

12 (range: 10-15) months
Active in care is defined as at least one ART visit in the defined window. Patients who have stopped ART and those who have transferred to another health facility with a known outcome (documented proof of a follow-up visit or laboratory test) are included. Participants who have died, are lost to followup, who have transferred to another facility without a known outcome (no documented proof of a follow-up visit or laboratory test), or are more than 2 months late for a scheduled consultation or medication pick-up with a reason (e.g. currently no money for a clinic visit, busy working in South Africa, etc.) are not counted as being active in care

Verbal autopsy to determine cause of death whenever possible; death certificates and autopsy reports are not required

We define participants lost to follow-up if they or their treatment buddies are more than 2 months late for a scheduled consultation or medication pick-up and we have no recent information about the participant

As above, a known outcome is documented proof of a follow-up visit or laboratory test at the new health facility

Serious adverse events graded according to the Division of AIDS Table for Grading the Severity of Adult and Pediatric Adverse Events, Version 2.0, November 2014 
Table 3 Secondary and exploratory endpoints of the VIBRA trial (Continued)

\begin{tabular}{lll}
\hline Definition & $\begin{array}{l}\text { Time point following } \\
\text { enrolment }\end{array}$ & Remarks \\
\hline
\end{tabular}

vs arm 1) on viral suppression $(<20$ copies $/ \mathrm{mL}$ )

\section{Assessment of acceptance of interventions

$$
\begin{aligned}
& \text { a) Acceptance of same-day ART } \\
& \text { initiation } \\
& \text { b) Acceptance of VIBRA model }
\end{aligned}
$$

Long-term follow-up

Long-term follow-up

\section{Within 1 month}

Proportion of participants who are active in care and virologically suppressed ( $<20$ copies $/ \mathrm{mL}$ )

The denominator of all proportions is the total number of study participants enrolled. Although this is a cluster-randomized trial, these endpoints will be analyzed at the individual level with binary outcomes

$A R T$ antiretroviral therapy, VHW village health worker, $V L$ viral load

of $80 \%$. Based on the assumption that we will recruit about 4 individuals per cluster, we will begin with 50 clusters per arm and can add more clusters as needed to reach our recruitment goals. All sample size calculations were done assuming a type 1 error rate of 0.05 and an intra-cluster correlation coefficient of 0.015 . If the true number of eligible individuals per cluster is lower and thus more clusters will be needed to reach the targeted minimum sample size, this will result in an increase of power. Table 4 provides estimates of the sample size under varying recruitment scenarios.

\section{Analyses}

Analyses will be performed following the CONSORT guidelines for cluster-randomized trials [47] and an intention-to-treat principle including all participants as randomized per cluster randomization. Clusters are the unit of randomization, but individuals are the unit of analysis. As we expect to have many clusters (i.e., villages) with few eligible individuals (i.e., HIV-positive but not on ART), an individual-level analysis is most appropriate. Multi-level

\begin{tabular}{|c|c|c|c|c|c|c|}
\hline \multirow[b]{2}{*}{ TIMEPOINT } & \multirow{2}{*}{$\begin{array}{c}\text { Enrolment } \\
0\end{array}$} & \multicolumn{3}{|c|}{ Post-allocation } & \multirow{3}{*}{\begin{tabular}{|} 
Close-out \\
12 months \\
(range: $10-15$ months)
\end{tabular}} & \multirow{3}{*}{$\begin{array}{l}\text { Long-term } \\
\text { Follow-up } \\
24 \text { months } \\
\text { (range: } 22-28 \text { months) }\end{array}$} \\
\hline & & $\begin{array}{l}\text { Within } \\
1 \text { month } \\
\text { (linkage to care) }\end{array}$ & $\begin{array}{l}\text { Within } \\
3 \text { month } \\
\text { (linkage to care) }\end{array}$ & $\begin{array}{c}6 \text { months } \\
\text { (range: } 5-8 \text { months) }\end{array}$ & & \\
\hline \multicolumn{5}{|l|}{ ENROLMENT: } & & \\
\hline eligibility screen & $\mathrm{X}$ & & & & & \\
\hline allocation (preset by cluster) & $\mathrm{x}$ & & & & & \\
\hline \multicolumn{7}{|l|}{ INTERVENTIONS: } \\
\hline VIBRA model (Intervention) & $\longmapsto$ & & & & $\longrightarrow \ldots+\ldots$ & 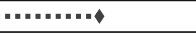 \\
\hline Standard of care (Control) & $\longmapsto$ & & & & $\Rightarrow \ldots \ldots \ldots$ & (n........ \\
\hline \multicolumn{7}{|l|}{ ASSESSMENTS: } \\
\hline Socio-demographic factors & $x$ & & & & & \\
\hline HIV knowledge $^{1}$ & $\mathrm{x}$ & & & & & \\
\hline tuberculosis screening $^{1}$ & $\mathrm{x}$ & $\mathrm{X}$ & $\mathrm{X}$ & $\mathrm{X}$ & $\mathrm{X}$ & $\mathrm{X}$ \\
\hline medical history $^{1}$ & $\mathrm{X}$ & $\mathrm{x}$ & $\mathrm{X}$ & $\mathrm{X}$ & $\mathrm{X}$ & $\mathrm{X}$ \\
\hline physical examination $^{1}$ & $x$ & $\mathrm{x}$ & $x$ & $\mathrm{X}$ & $\mathrm{X}$ & $\mathrm{x}$ \\
\hline WHO staging ${ }^{2}$ & $\mathrm{x}$ & $\mathrm{x}$ & $\mathrm{x}$ & $\mathrm{X}$ & $\mathrm{X}$ & $\mathrm{X}$ \\
\hline CD4 & $x$ & & & & $\mathrm{x}$ & $(X)$ \\
\hline $\mathrm{CrAg}^{3}$ & $(X)$ & & & & & \\
\hline creatinine & $\mathrm{X}$ & & & $\mathrm{X}$ & $\mathrm{X}$ & $\mathrm{X}$ \\
\hline haemoglobin & $\mathrm{X}$ & & & $(X)$ & $(X)$ & $(X)$ \\
\hline adherence counseling & $\mathrm{x}$ & $\mathrm{X}$ & $\mathrm{x}$ & $\mathrm{x}$ & $\mathrm{x}$ & $\mathrm{x}$ \\
\hline readiness assessment $^{1}$ & $\mathrm{X}$ & & & & & \\
\hline dispensing of $\mathrm{ART}^{4}$ & $x$ & $\mathrm{X}$ & $\mathrm{X}$ & $\mathrm{x}$ & $\mathrm{X}$ & $\mathrm{X}$ \\
\hline viral load & $x$ & & & $\mathrm{X}$ & $x$ & $\mathrm{X}$ \\
\hline plasma for storage ( $=3$ EDTA tubes for GRT) ${ }^{5}$ & $\mathrm{X}$ & & & $(X)$ & $(X)$ & $(X)$ \\
\hline \multicolumn{7}{|c|}{$\begin{array}{l}\text { Fig. } 2 \text { SPIRIT flow diagram for the VIBRA trial. } \\
\text { Footnotes: }{ }^{1} \text { see Additional file } 1,{ }^{2} \text { only at clinic-based follow-up visits, }{ }^{3} \text { for all participants with a baseline CD4-count }<200 \text { cells/mcL (see also Table } 2 \text { ), } \\
{ }^{4} \text { incl. CTX and IPT (+B6) and other co-infection (prophylaxis) medication if appropriate, }{ }^{5} \text { See chapter Additional research within the project }\end{array}$} \\
\hline
\end{tabular}
statistical models will be used to adjust for the clustered data. The following analysis sets will be used in this trial: 
Table 4 Sample size estimations for the VIBRA trial

\begin{tabular}{|c|c|c|c|c|c|c|}
\hline $\begin{array}{l}\text { Control rate of } \\
\text { viral suppression }\end{array}$ & $\begin{array}{l}\text { Intervention rate of } \\
\text { viral suppression }\end{array}$ & Power & $\begin{array}{l}\text { Intra-cluster correlation } \\
\text { coefficient }\end{array}$ & $\begin{array}{l}\text { Average number of eligible } \\
\text { individuals per cluster }\end{array}$ & $\begin{array}{l}\text { Total number } \\
\text { of clusters }\end{array}$ & $\begin{array}{l}\text { Total } \\
\text { sample size }\end{array}$ \\
\hline 0.5 & 0.7 & 0.9 & 0.015 & 4 & 120 & 478 \\
\hline 0.5 & 0.7 & 0.9 & 0.015 & 3 & 160 & 478 \\
\hline 0.5 & 0.7 & 0.9 & 0.015 & 2 & 240 & 478 \\
\hline 0.5 & 0.7 & 0.8 & 0.015 & 4 & 66 & 262 \\
\hline 0.5 & 0.7 & 0.8 & 0.015 & 3 & 88 & 262 \\
\hline 0.5 & 0.7 & 0.8 & 0.015 & 2 & 130 & 262 \\
\hline 0.5 & 0.75 & 0.9 & 0.015 & 4 & 49 & 195 \\
\hline 0.5 & 0.75 & 0.9 & 0.015 & 3 & 65 & 195 \\
\hline 0.5 & 0.75 & 0.9 & 0.015 & 2 & 98 & 195 \\
\hline 0.5 & 0.75 & 0.8 & 0.015 & 4 & 33 & 130 \\
\hline 0.5 & 0.75 & 0.8 & 0.015 & 3 & 44 & 130 \\
\hline 0.5 & 0.75 & 0.8 & 0.015 & 2 & 65 & 130 \\
\hline
\end{tabular}

1. Intention-to-treat set: All study participants will be evaluated according to their cluster assignment at randomization.

2. Cluster per-protocol set: This set includes all participants from clusters that completed the study without a major protocol deviation.

3. Individual per-protocol set: This set includes all participants who completed the study without a major protocol deviation.

The primary analysis for the VIBRA study will be the comparison of viral suppression at 12 months after the offer of same-day ART initiation in the intention-to-treat set. The primary analysis will use a multi-level logistic regression model to assess the difference between the arms, adjusted for the prespecified randomization stratification factors and the clustering according to village. Moreover, we will adjust for the most important baseline characteristics if found to be unbalanced (gender, age, known HIV status vs newly diagnosed, ever on ART vs never on ART, CD4 count) and other factors found to be largely unbalanced between the intervention and control clusters.

Baseline characteristics will be presented according to randomized groups and no formal testing will be performed. Categorical variables will be described as absolute and relative frequencies and continuous variables as medians and interquartile ranges. As with the primary analysis, secondary endpoints will be analyzed with a multilevel logistic regression model. All results will be presented as odds ratios and their respective $95 \%$ confidence intervals. Several sensitivity analyses will be conducted. We will do a quadrature check of the model fit and if found to be unreliable, we will utilize generalized estimating equations. The effect of sociodemographic and clinical determinants (age groups, gender, education status, employment status, WHO stage, CD4 count, tuberculosis status, CAGE status,
HIV/ART history, and HIV knowledge) on key study outcomes will be assessed by including interaction terms in the model. If an interaction term is found to be significant, effect estimates will be summarized descriptively by subgroup. As the study is not powered for these pre-planned subgroup analyses, these results will be considered exploratory. Where data are missing in important covariates, multiple imputation will be utilized and the results compared to models ignoring missing data.

All analyses will be done using Stata (version 14, Stata Corporation, Austin, Texas, USA), using two-sided $p$ values and a significance level of 0.05 .

\section{Monitoring, auditing, and data safety and monitoring board}

At least one external monitoring visit will assess adherence to the approved trial protocol, and the accuracy of completed case report forms and the electronic dataset. The VIBRA trial is researching the implementation of a treatment. The safety profiles of all drugs used are well known, and the intervention does not include any new drugs. Moreover, there have been encouraging results from similar trials in Uganda, Kenya, and Tanzania [4850]. Thus, major adverse effects on patients' health from this intervention are not expected. Participants in the VIBRA model can opt to switch back to usual care or be referred to facility-based care at any time during the trial period. Therefore, we do not intend to establish a data safety and monitoring board. However, a separate, detailed safety monitoring plan has been developed to handle adverse events and serious adverse events in line with Swiss and Basotho ethics regulations. Adverse events and serious adverse events will be graded according to the Division of AIDS Table for Grading the Severity of Adult and Pediatric Adverse Events, 
Version 2.0., November 2014 [51] and managed according to the standard procedure for each study site following the national guidelines [19]. The study physicians are responsible for all safety procedures. If a participant reports an adverse event of grade 2 or higher at their last study visit, they will remain under observation by the study physicians, even after study termination, until the adverse event is resolved or stabilized.

\section{Discussion}

Effective and differentiated strategies are needed to improve the HIV care cascade, especially in rural settings. Despite successful upscaling of ART, the financial, human, and physical resources available to fulfill the UNAIDS targets are unlikely to grow relative to the increasing number of people on ART $[52,53]$. Therefore, there is global consensus that new differentiated care and service delivery models that increase the capacity, efficiency, and costeffectiveness of delivering ART without reducing quality of care are urgently needed $[22,39,54]$.

Shifting tasks to lay health workers in the community is a promising approach and in line with the current UNAIDS initiative [42]. However, at community level, task-shifting usually focuses on adherence monitoring, not the provision of antiretroviral drugs [29, 55-61]. A few programs use community health workers or VHWs to supply ART at home to patients [48, 49, 62-67]. This is, however, a resource-intensive intervention, there may be difficulties with confidentiality and stigma relating to home visits, patients must be at home during these visits, and their homes need to be readily accessible. These factors are unfavorable in a setting like Lesotho with limited resources and a population scattered around a vast mountainous area. Moreover, these models include only stable patients. The definition of a stable patient can be challenging, and may lead to late inclusion in these models. Differentiated care should be designed not only for stable patients but also for patients who would otherwise not engage in care [23].

The VIBRA model entails a second feature, SMS reminders and notifications. These have been studied widely in sub-Saharan Africa and lead to increased adherence and engagement in care [68-74]. However, sustainability is questionable, especially when reminders must be implemented manually. Our setting in Lesotho allows SMS messages to be sent automatically from an established database that is connected to the governmental district laboratory database with access to VL results from all study districts. Moreover, while most studies use standardized messages reminding the patient about their drug intake or clinic visits, the SMS intervention in the VIBRA model will go one step further. It will automatically generate and send notifications that are individually tailored according to the VL level, indicating the next steps of action for the patient.

This trial has several limitations. First, the study design does not allow for the evaluation of the effectiveness of each individual feature of the VIBRA model. Second, as in most operational research studies, we will have little control over what happens in our standard care arm. Standard care for HIV continues to evolve rapidly with frequent guideline revisions and the implementation of other differentiated ART service delivery models. Third, due to the nature of this pragmatic implementation trial, it is not possible to fully blind participants or staff to the intervention. However, allocation will be concealed from the study participants due to the cluster randomization design, which implies randomization before participant inclusion.

In summary, the VIBRA trial evaluates a unique differentiated ART delivery model with community-based drug refills and follow-ups after a home-based diagnosis and ART initiation in combination with a tailored SMS service. As most countries in sub-Saharan Africa have cadres like the VHW program in Lesotho, this model-if shown to be effective-has the potential to be scaled up. The system impact evaluation will provide valuable cost estimations, and the qualitative research will suggest how the model could be modified further to optimize its impact.

\section{Trial status and recruitment}

The trial was launched on 16 August 2018 in both study districts. Based on the experience of previous HIV testing campaigns and the CASCADE trial, we assumed that we would reach the required minimum target sample size in about 6-8 months. The initial study protocol, version 5, was submitted to the ethics committees in Lesotho (February 2018) and Switzerland (April 2018), and approved on 25 April 2018 (Lesotho) and 8 May 2018 (Switzerland). Meanwhile, two minor amendments to the study protocol were submitted and have been accepted. The current protocol is version 7 and was approved in October 2018.

\section{Additional file}

Additional file 1: GET ON electronic case report form. (PDF $1050 \mathrm{~kb}$ )

Additional file 2: SPIRIT 2013 Checklist: Recommended items to address in a clinical trial protocol and related documents. (PDF $82 \mathrm{~kb}$ )

\section{Abbreviations}

ART: Antiretroviral therapy; CAN: Community ART nurse; CrAg: Cryptococcal antigen; GET ON: Getting Towards Ninety; HIV: Human immunodeficiency virus; HOSENG: Home-based Self-testing; SMS: Short Message Service;

TDF: Tenofovir disoproxil fumarate; UNAIDS: United Nations Program on HIV/ AIDS; VHW: Village health worker; VIBRA: Village-based Refill of ART; VL: Viral load; WHO: World Health Organization 


\section{Acknowledgements}

We would like to recognize the hard work and valuable contributions of the study staff in both districts, the tireless support of the entire SolidarMed team in Lesotho, as well as the precious assistance of the data management team at the Swiss Institute of Tropical and Public Health. We thank the participating health facilities and the laboratory personnel for their dedication to the research and we gratefully acknowledge the study participants.

\section{Authors' contributions}

NDL is the principal investigator of this trial. AA, JM, LK, NDL, TIL, and TRG conceived and designed the trial. BLN, FT, MB, MBa, MK, and MKa were involved in critical revising the article for important intellectual content. KT and TK provide laboratory expertise. All authors read, revised, and approved the final manuscript.

\section{Funding}

This trial is predominantly funded by a grant from the Swiss National Science Foundation (grant IZ07Z0_160876/1) and the Eccellenza Professorship Grant of the Swiss National Science Foundation (grant PCEFP3_181355), both obtained by NDL. AA receives a salary through a grant from the MD/PhD program of the Swiss National Science Foundation (grant 323530_177576). Further funding came from a grant from the Stiftung für Infektiologie beider Basel, obtained by NDL. The Swiss Institute of Tropical and Public Health is the sponsor of the study. The study is embedded in the SolidarMed country program and thus benefits from logistics and human resources from SolidarMed Lesotho.

The funding sources have no role in the design of the study, and will not be involved in data collection, data analysis, interpretation of the results, or writing of the manuscript.

\section{Availability of data and materials}

The datasets used and analyzed during the study will be available from the corresponding author on reasonable request.

\section{Ethics approval and consent to participate}

This trial has been approved by the National Health Research and Ethics Committee of the Ministry of Health of Lesotho (ID06-2018) and the ethics committee in Switzerland (Ethikkomission Nordwest- und Zentralschweiz; 2018-00283).

Details of the consent process of the testing campaign are provided in the HOSENG study protocol. If a household member is eligible for inclusion into the VIBRA trial, the study nurse will obtain separate written informed consent and then collect the participant's data and draw blood for storage and additional analyses. The informed consent forms for the control and intervention clusters are different but do not indicate the cluster allocation. Allocation to the cluster arm is concealed to minimize the risk of selection bias. Illiterate participants provide a thumb-print and a witness (independent of the trial and $>21$ years old), chosen by the participant, will co-sign the informed consent form. For participants aged $<18$ years, a literate caregiver (someone who takes care of them and $>21$ years old) provides consent. The informed consent form is in the local language, Sesotho, and each participant is given a copy. Study participants have the right to withdraw their consent at any time without giving reasons. If a participant does withdraw, only data collected until the time of withdrawal will be used for research purposes (fully anonymized with the identifier removed)

Participation in this study is not anticipated to cause any substantial additional risk or cost to the participants. Therefore, we will not pay compensation to them. Free AirTime (local prepaid money for cellphone usage) will be provided to the VHWs for their duties within the study. The VHWs have a central role in this new differentiated ART care and delivery model. Besides providing the basic supplies required for their work (i.e., a lockable drawer or cabinet to store medication and patient documents), we will support them with money for transportation to make sure the link between VHWs and the health facility is guaranteed. All VHWs who do not have a cellphone will receive a cellphone to stay in close contact with their responsible CAN. We will consider implementing stepwise remuneration for nurses at the health facilities for the clinic-based ART visits by our study participants during the follow-up.

The results of this research project will be shared at three levels: (1) district level, during meetings headed by the district health management team, (2) national level, at the national research symposium of the Ministry of Health, and (3) international level through presentations at conferences and publication in peer-reviewed journals. The current version of the recommendations of the International Committee of Medical Journal Editors [75] will be followed regarding the eligibility of authorship and we do not intend to use a professional writer.

\section{Consent for publication}

Not applicable.

\section{Competing interests}

The Division of Infectious Diseases and Hospital Epidemiology, University Hospital Basel, under the lead of MB, receives unrestricted education and research grants from Gilead, MSD, Janssen, and ViiV. All other authors declare that they have no competing interests.

\section{Author details}

${ }^{1}$ Clinical Research Unit, Department of Medicine, Swiss Tropical and Public Health Institute, Socinstrasse 57, 4051 Basel, Switzerland. ${ }^{2}$ University of Basel, 4051 Basel, Switzerland. ${ }^{3}$ Division of Infectious Diseases and Hospital Epidemiology, University Hospital Basel, 4051 Basel, Switzerland. ${ }^{4}$ SolidarMed, Swiss Organization for Health in Africa, Butha-Buthe, Lesotho. ${ }^{5}$ Butha-Buthe Government Hospital, Butha-Buthe, Lesotho. ${ }^{6}$ Molecular Virology, Department of Biomedicine, University of Basel, 4051 Basel, Switzerland.

Received: 5 January 2019 Accepted: 10 June 2019

Published online: 22 August 2019

\section{References}

1. Nachega JB, Uthman OA, Rio C, Mugavero MJ, Rees H, Mills EJ. Addressing the Achilles' heel in the HIV care continuum for the success of a test-andtreat strategy to achieve an AIDS-free generation. Clin Infect Dis. 2014;59. https://doi.org/10.1093/cid/ciu299.

2. Fox MP, MPA SR. Retention of Adult Patients on Antiretroviral Therapy in Low- and Middle-Income Countries: Systematic Review and Meta-analysis 2008-2013. J Acquir Immune Defic Syndr 1999. 2015;69(1):98-108. https:// doi.org/10.1097/QAl.0000000000000553.

3. Rosen S, Fox MP. Retention in HIV Care between Testing and Treatment in Sub-Saharan Africa: A Systematic Review. Bartlett J, ed. PLoS Med. 2011;8(7): e1001056. https://doi.org/10.1371/journal.pmed.1001056.

4. Kranzer K, Govindasamy D, Ford N, Johnston V, Lawn SD. Quantifying and addressing losses along the continuum of care for people living with HIV infection in sub-Saharan Africa: a systematic review. J Int AIDS Soc. 2012;15. https://doi.org/10.7448/IAS.15.2.17383.

5. Mugglin C, Estill J, Wandeler G, et al. Loss to programme between HIV diagnosis and initiation of antiretroviral therapy in sub-Saharan Africa: systematic review and meta-analysis. Trop Med Int Health TM IH. 2012; 17(12):1509-20. https://doi.org/10.1111/j.1365-3156.2012.03089.x.

6. Ruzagira E, Baisley K, Kamali A, Biraro S, Grosskurth H, the Working Group on Linkage to HIV Care. Linkage to HIV care after home-based HIV counselling and testing in sub-Saharan Africa: a systematic review. Tropical Med Int Health. 2017. https://doi.org/10.1111/tmi.12888.

7. Plazy M, Farouki KE, Iwuji C, et al. Access to HIV care in the context of universal test and treat: challenges within the ANRS 12249 TasP clusterrandomized trial in rural South Africa. J Int AIDS Soc. 2016;19(1):20913. https://doi.org/10.7448/IAS.19.1.20913.

8. Rosen S, Fox MP, Larson BA, et al. Accelerating the Uptake and Timing of Antiretroviral Therapy Initiation in Sub-Saharan Africa: An Operations Research Agenda. PLoS Med. 2016;13(8):e1002106. https://doi.org/10.1371/ journal.pmed.1002106.

9. Chimbindi $N$, Bor J, Newell M-L, et al. Time and money: the true costs of health care utilization for patients receiving 'free' HIV/TB care and treatment in rural KwaZulu-Natal. J Acquir Immune Defic Syndr 1999. 2015;70(2):e5260. https://doi.org/10.1097/QAl.0000000000000728.

10. Govindasamy D, Ford N, Kranzer K. Risk factors, barriers and facilitators for linkage to antiretroviral therapy care: a systematic review. AIDS. 2012;26(16).

11. Kolawole GO, Gilbert HN, Dadem NY, et al. Patient Experiences of Decentralized HIV Treatment and Care in Plateau State, North Central Nigeria: A Qualitative Study. AIDS Res Treat. 2017;2017:10 https://doi.org/10.1155/2017/2838059.

12. Ware NC, Wyatt MA, Geng EH, et al. Toward an understanding of disengagement from HIV treatment and care in sub-Saharan Africa: a 
qualitative study. PLoS Med. 2013;10(1):e1001369; discussion e1001369. https://doi.org/10.1371/journal.pmed.1001369.

13. Hardon AP, Akurut D, Comoro C, et al. Hunger, waiting time and transport costs: time to confront challenges to ART adherence in Africa. AIDS Care. 2007;19(5):658-65. https://doi.org/10.1080/09540120701244943.

14. Brundisini F, Giacomini M, DeJean D, Vanstone M, Winsor S, Smith A. Chronic Disease Patients' Experiences With Accessing Health Care in Rural and Remote Areas. Ont Health Technol Assess Ser. 2013:13(15):1-33.

15. Moyer CA, Mustafa A. Drivers and deterrents of facility delivery in subSaharan Africa: a systematic review. Reprod Health. 2013;10(1):40. https://doi. org/10.1186/1742-4755-10-40.

16. Tuller DM, Bangsberg DR, Senkungu J, Ware NC, Emenyonu N, Weiser SD. Transportation costs impede sustained adherence and access to HAART in a clinic population in southwestern Uganda: a qualitative study. AIDS Behav. 2010;14(4):778-84. https://doi.org/10.1007/s10461-009-9533-2.

17. WHO. WHO. TASK SHIFTING: rational redistribution of tasks among health workforce teams. Global Recommendations and Guidelines. http://www. who.int/healthsystems/TTR-TaskShifting.pdf?ua=1. Accessed 26 July 2017.

18. UNAIDS. Joint United Nations Programme on HIV/AIDS (UNAIDS). ENDING AIDS - Progress Towards the 90-90-90 Targets. GLOBAL AIDS UPDATE 2017. http://www.unaids.org/sites/default/files/media_asset/Global_AIDS_update_ 2017_en.pdf. Accessed 24 July 2017.

19. Lesotho 2016 National ART Guidelines. https:/aidsfree.usaid.gov/sites/ default/files/lesotho_art_2016.pdf. Accessed 15 Sept 2016.

20. Bärnighausen T, Bloom DE, Humair S. Human resources for treating HIV/ AIDS: needs, capacities, and gaps. AIDS Patient Care STDs. 2007;21(11):799812. https://doi.org/10.1089/apc.2007.0193.

21. James H McMahon, Julian H Elliott, Silvia Bertagnolio, Rachel Kubiak \& Michael R Jordan. Viral suppression after 12 months of antiretroviral therapy in low- and middle-income countries: a systematic review. Bulletin of the World Health Organization - 12-112946.pdf. http://www.who.int/bulletin/ volumes/91/5/12-112946.pdf. Accessed 26 May 2017.

22. Grimsrud A, Barnabas RV, Ehrenkranz P, Ford N. Evidence for scale up: the differentiated care research agenda. J Int AIDS Soc. 2017;20:22024. https:// doi.org/10.7448/IAS.20.5.22024.

23. Grimsrud A, Bygrave $H$, Doherty $M$, et al. Reimagining HIV service delivery: the role of differentiated care from prevention to suppression. J Int AIDS Soc. 2016;19(1). https://doi.org/10.7448/IAS.19.1.21484.

24. Labhardt ND, Ringera I, Lejone TI, et al. Effect of Offering Same-Day ART vs Usual Health Facility Referral During Home-Based HIV Testing on Linkage to Care and Viral Suppression Among Adults With HIV in Lesotho: The CASCADE Randomized Clinical Trial. JAMA. 2018. https://doi.org/10.1001/jama.2018.1818.

25. Callaghan M, Ford N, Schneider H. A systematic review of task- shifting for HIV treatment and care in Africa. Hum Resour Health. 2010;8:8-8. https://doi. org/10.1186/1478-4491-8-8

26. Philips $M$, Zachariah $R$, Venis $S$. Task shifting for antiretroviral treatment delivery in sub-Saharan Africa: not a panacea. Lancet. 2008;371(9613):682-4. https://doi.org/10.1016/50140-6736(08)60307-4.

27. Lewin S, Dick J, Pond P, et al. Lay health workers in primary and community health care. Cochrane Database Syst Rev. 2005;(1). https://doi.org/10.1002/ 14651858.CD004015.pub2.

28. Chan AK, Mateyu G, Jahn A, et al. Outcome assessment of decentralization of antiretroviral therapy provision in a rural district of Malawi using an integrated primary care model. Tropical Med Int Health. 2010;15:90-7. https://doi.org/10.1111/j.1365-3156.2010.02503.x.

29. Bedelu M, Ford N, Hilderbrand K, Reuter H. Implementing Antiretroviral Therapy in Rural Communities: The Lusikisiki Model of Decentralized HIV/AIDS Care. J Infect Dis. 2007;196(Supplement_3):S464-8. https:/doi.org/10.1086/521114.

30. Fatti G, Grimwood A, Bock P. Better Antiretroviral Therapy Outcomes at Primary Healthcare Facilities: An Evaluation of Three Tiers of ART Services in Four South African Provinces. Ugarte-Gil CA. PLoS One. 2010;5(9):e12888. https://doi.org/10.1371/journal.pone.0012888.

31. Bemelmans $M$, Van Den Akker T, Ford $N$, et al. Providing universal access to antiretroviral therapy in Thyolo, Malawi through task shifting and decentralization of HIV/AIDS care. Tropical Med Int Health. 2010;15(12): 1413-20. https://doi.org/10.1111/j.1365-3156.2010.02649.x.

32. Reidy WJ, Sheriff M, Wang C, et al. Decentralization of HIV care and treatment services in Central Province, Kenya. J Acquir Immune Defic Syndr 1999. 2014;67(1):e34-40. https://doi.org/10.1097/QAl.0000000000000264.

33. Miyano S, Syakantu G, Komada K, Endo H, Sugishita T. Cost-effectiveness analysis of the national decentralization policy of antiretroviral treatment programme in Zambia. Cost Eff Resour Alloc CE. 2017;15. https://doi.org/10. 1186/s12962-017-0065-8.

34. Hagströmer $\mathrm{O}$, Lundstedt L, Balcha TT, Björkman P. Decentralised paediatric HIV care in Ethiopia: a comparison between outcomes of patients managed in health centres and in a hospital clinic. Glob Health Action. 2013;6. https:// doi.org/10.3402/gha.v6i0.22274.

35. Kredo T, Adeniyi FB, Bateganya M, Pienaar ED. Task shifting from doctors to non-doctors for initiation and maintenance of antiretroviral therapy. Cochrane Database Syst Rev. 2014;7:CD007331. https://doi.org/10.1002/ 14651858.CD007331.pub3.

36. Barr D, Odetoyinbo M, Mworeko L, Greenberg J. The leadership of communities in HIV service delivery. AIDS Lond Engl. 2015;29(Suppl 2):S1217. https://doi.org/10.1097/QAD.0000000000000717.

37. Austin-Evelyn K, Rabkin M, Macheka T, et al. Community health worker perspectives on a new primary health care initiative in the Eastern Cape of South Africa. PLoS One. 2017;12(3):e0173863. https:/doi.org/10.1371/journal.pone.0173863.

38. UNAIDS/PCB (38)/16.14; CRP1. http://www.unaids.org/sites/default/files/media_ asset/20160607_UNAIDS_PCB38_16-14_BN_EN.pdf. Accessed 6 Sept 2017.

39. PowerPoint Presentation - USAID-Community-Health-Framework_Version-10_October-28th-2015.pdf. http://chwcentral.org/sites/default/files/USAIDCommunity-Health-Framework_Version-1-0_October-28th-2015.pdf. Accessed 6 Sept 2017.

40. Barker C, Dutta A, Klein K. Can differentiated care models solve the crisis in HIV treatment financing? Analysis of prospects for 38 countries in sub-Saharan Africa. J Int AIDS Soc. 2017;20(5). https://doi.org/10.7448/ias.20.5.21648.

41. Lazarus JV, Safreed-Harmon K, Nicholson J, Jaffar S. Health service delivery models for the provision of antiretroviral therapy in sub-Saharan Africa: a systematic review. Trop Med Int Health TM IH. 2014;19(10):1198-215. https://doi.org/10.1111/tmi.12366.

42. Gilks CF, Crowley S, Ekpini R, et al. The WHO public-health approach to antiretroviral treatment against HIV in resource-limited settings. Lancet. 368(9534):505-10. https://doi.org/10.1016/S0140-6736(06)69158-7.

43. UNAIDS and CSD endorse creation of 2 million CHWs in support of 90-90-90 Center for Sustainable Development. http://csd.columbia.edu/2017/02/17/ unaids-and-csd-endorse-creation-of-2-million-chws/. Accessed 6 Sept 2017.

44. Miller H. Kingdom of Lesotho - Millennium Development Goals Status Report 2013; 2013. p. 125.

45. LePHIA report 2016-2017_summary sheet. https://phia.icap.columbia.edu/ wp-content/uploads/2018/02/Lesotho-Summary-Sheet_A4.2.7.18.HR_.pdf. Accessed 27 Aug 2018.

46. Andriessen PP, van der Endt RP, Gotink MH. The Village Health Worker Project in Lesotho: An Evaluation. Trop Dr. 1990;20(3):111-3. https://doi.org/ 10.1177/004947559002000307.

47. LESOTHO. 2016 HTS GUIDELINES. 2016.

48. Campbell MK, Piaggio G, Elbourne DR, Altman DG. Consort 2010 statement: extension to cluster randomised trials. BMJ. 2012;345. https://doi.org/10. 1136/bmj.e5661.

49. Jaffar $\mathrm{S}$, Amuron B, Foster $\mathrm{S}$, et al. Rates of virological failure in patients treated in a home-based versus a facility-based HIV-care model in Jinja, southeast Uganda: a cluster-randomised equivalence trial. Lancet. 2009; 374(9707):2080-9. https://doi.org/10.1016/S0140-6736(09)61674-3.

50. Selke HM, Kimaiyo S, Sidle JE, et al. Task-Shifting of Antiretroviral Delivery From Health Care Workers to Persons Living With HIV/AIDS: Clinical Outcomes of a Community-Based Program in Kenya. JAIDS J Acquir Immune Defic Syndr. 2010;55(4).

51. Geldsetzer P, Francis JM, Ulenga N, et al. The impact of community health workerled home delivery of antiretroviral therapy on virological suppression: a noninferiority cluster-randomized health systems trial in Dar es Salaam, Tanzania. BMC Health Serv Res. 2017;17(1):160. https:/doi.org/10.1186/s12913-017-2032-7.

52. DAIDS_AE_Grading_Table_v2.0_NOV2014 - daids_ae_grading_table_v2_ nov2014.pdf. https://rsc.tech-res.com/docs/default-source/safety/daids_ae_ grading_table_v2_nov2014.pdf. Accessed 9 Dec 2017.

53. Wexler A, Jul 20 ELU, Jul 152016 | Published:, 2016. Financing the Response to HIV in Low- and Middle-Income Countries: International Assistance from Donor Governments in 2015 - Executive Summary. Henry J Kais Fam Found. July 2016. https://www.kff.org/report-section/financing-the-response-to-hivin-low-and-middle-income-countries-international-assistance-from-donorgovernments-in-2015-executive-summary/. Accessed 23 Sept 2018.

54. Atun R, Chang AY, Ogbuoji O, et al. Long-term financing needs for HIV control in sub-Saharan Africa in 2015-2050: a modelling study. BMJ Open. 2016;6(3). https://doi.org/10.1136/bmjopen-2015-009656. 
55. Ehrenkranz PD, Calleja JM, El-Sadr W, et al. A pragmatic approach to monitor and evaluate implementation and impact of differentiated ART delivery for global and national stakeholders. J Int AIDS Soc. 2018;21(3): e25080. https://doi.org/10.1002/jia2.25080.

56. Cohen R, Lynch S, Bygrave $\mathrm{H}$, et al. Antiretroviral treatment outcomes from a nurse-driven, community-supported HIV/AIDS treatment programme in rural Lesotho: observational cohort assessment at two years. J Int AIDS Soc. 2009;12:23. https://doi.org/10.1186/1758-2652-12-23.

57. Abaasa AM, Todd J, Ekoru K, et al. Good adherence to HAART and improved survival in a community HIV/AIDS treatment and care programme: the experience of The AIDS Support Organization (TASO), Kampala, Uganda. BMC Health Serv Res. 2008;8:241. https://doi.org/10.1186/1472-6963-8-241.

58. Nachega JB, Chaisson RE, Goliath R, et al. Randomized Controlled Trial of Trained Patient-Nominated Treatment Supporters Providing Partial Directly Observed Antiretroviral Therapy. AIDS Lond Engl. 2010;24(9):1273-80. https://doi.org/10.1097/QAD.0b013e328339e20e.

59. Igumbor JO, Scheepers E, Ebrahim R, Jason A, Grimwood A. An evaluation of the impact of a community-based adherence support programme on ART outcomes in selected government HIV treatment sites in South Africa. AIDS Care. 2011;23(2):231-6. https://doi.org/10.1080/09540121.2010.498909.

60. Rich ML, Miller AC, Niyigena P, et al. Excellent Clinical Outcomes and High Retention in Care Among Adults in a Community-Based HIV Treatment Program in Rural Rwanda. JAIDS. J Acquir Immune Defic Syndr. 2012;59(3).

61. Chang LW, Kagaayi J, Nakigozi G, et al. Effect of Peer Health Workers on AIDS Care in Rakai, Uganda: A Cluster-Randomized Trial. Kissinger P, ed. PLoS One. 2010;5(6):e10923. https://doi.org/10.1371/journal.pone.0010923.

62. Torpey KE, Kabaso ME, Mutale LN, et al. Adherence Support Workers: A Way to Address Human Resource Constraints in Antiretroviral Treatment Programs in the Public Health Setting in Zambia. Pai M, ed. PLoS ONE. 2008; 3(5):e2204. https://doi.org/10.1371/journal.pone.0002204.

63. Amuron B, Levin J, Birunghi J, et al. Mortality in an antiretroviral therapy programme in Jinja, south-east Uganda: a prospective cohort study. AIDS Res Ther. 2011;8:39. https://doi.org/10.1186/1742-6405-8-39.

64. Wools-Kaloustian KK, Sidle JE, Selke HM, et al. A model for extending antiretroviral care beyond the rural health centre. J Int AIDS Soc. 2009;12:22. https://doi.org/10.1186/1758-2652-12-22.

65. Kipp W, Konde-Lule J, Saunders LD, et al. Antiretroviral Treatment for HIV in Rural Uganda: Two-Year Treatment Outcomes of a Prospective Health Centre/Community-Based and Hospital-Based Cohort. Myer L. PLoS One. 2012;7(7):e40902. https://doi.org/10.1371/journal.pone.0040902.

66. Weidle PJ, Wamai N, Solberg P, et al. Adherence to antiretroviral therapy in a home-based AIDS care programme in rural Uganda. Lancet. 2006; 368(9547):1587-94. https://doi.org/10.1016/S0140-6736(06)69118-6.

67. Mermin J, Were W, Ekwaru JP, et al. Mortality in HIV-infected Ugandan adults receiving antiretroviral treatment and survival of their HIV-uninfected children: a prospective cohort study. Lancet. 2008;371(9614):752-9. https:// doi.org/10.1016/S0140-6736(08)60345-1.

68. Moore DM, Yiannoutsos CT, Musick BS, et al. Determinants of early and late mortality among HIV-infected individuals receiving home-based antiretroviral therapy in rural Uganda. J Acquir Immune Defic Syndr 1999. 2011;58(3):289-96. https://doi.org/10.1097/QAl.0b013e3182303716.

69. Lester RT, Ritvo P, Mills EJ, et al. Effects of a mobile phone short message service on antiretroviral treatment adherence in Kenya (WelTel Kenya1): a randomised trial. Lancet. 376(9755):1838-45. https://doi.org/10.1016/S01406736(10)61997-6.

70. Pop-Eleches $\mathrm{C}$, Thirumurthy $\mathrm{H}$, Habyarimana JP, et al. Mobile phone technologies improve adherence to antiretroviral treatment in a resourcelimited setting: a randomized controlled trial of text message reminders. AIDS Lond Engl. 2011;25(6):825-34. https://doi.org/10.1097/QAD. Ob013e32834380c1.

71. Chang LW, Kagaayi J, Nakigozi G, et al. Responding to the human resource crisis: peer health workers, mobile phones, and HIV care in Rakai, Uganda. AIDS Patient Care STDs. 2008;22(3):173-4. https://doi.org/10.1089/apc.2007.0234.

72. Fjeldsoe BS, Marshall AL, Miller YD. Behavior change interventions delivered by mobile telephone short-message service. Am J Prev Med. 2009;36(2): 165-73. https://doi.org/10.1016/j.amepre.2008.09.040.

73. Haberer JE, Kiwanuka J, Nansera D, Wilson IB, Bangsberg DR. Challenges in using mobile phones for collection of antiretroviral therapy adherence data in a resource-limited setting. AIDS Behav. 2010;14(6):1294-301. https://doi. org/10.1007/s10461-010-9720-1.
74. Mukund Bahadur K-C, Murray PJ. Cell phone short messaging service (SMS) for HIV/AIDS in South Africa: a literature review. Stud Health Technol Inform. 2010;160(Pt 1):530-4.

75. ICMJE | Recommendations for the Conduct, Reporting, Editing, and Publication of Scholarly work in Medical Journals. http://www.icmje.org/ recommendations/. Accessed 11 Sept 2017.

76. Amstutz A, Lejone Tl, Khesa $L$, et al. The HOSENG trial - Effect of the provision of oral self-testing for absent and refusing individuals during a door-to-door HIV-testing campaign on testing coverage: protocol of a cluster-randomized clinical trial in rural Lesotho. Trials 2019; 20. https://doi. org/10.1186/s13063-019-3469-2.

\section{Publisher's Note}

Springer Nature remains neutral with regard to jurisdictional claims in published maps and institutional affiliations.
Ready to submit your research? Choose BMC and benefit from:

- fast, convenient online submission

- thorough peer review by experienced researchers in your field

- rapid publication on acceptance

- support for research data, including large and complex data types

- gold Open Access which fosters wider collaboration and increased citations

- maximum visibility for your research: over $100 \mathrm{M}$ website views per year

At BMC, research is always in progress.

Learn more biomedcentral.com/submissions 